\title{
Airworthiness Management and Engineering Curriculum and its Implementation
}

\author{
Jianbo $\mathrm{Hu}$ \\ Air Force Engineering University, XiAn, PRC, 710038
}

Key words: airworthiness, curriculum, system safety

\begin{abstract}
Airworthiness considerations are critically important in the design, development, maintenance, and management of civil and military aircraft. A solid understanding of airworthiness standards, certification criteria, verification methods and management approach are key pieces of knowledge for aerospace managers and engineers who are actively engaged in aircraft design, development, maintenance and management. Recently, it is necessary for many engineering and management schools to incorporate airworthiness considerations of civil and military aircraft into the academic curricula. Young managers and engineers who enter a career in aircraft field may lack critical information with regard to certification requirements that impact the aircraft design and service process. Incorporating airworthiness into the academic curriculum will produce mangers and engineers who understand how airworthiness considerations impact aircraft design and management, and who are equipped to resolve airworthiness-related challenges.
\end{abstract}

\section{Introduction}

Safety is the key for aircraft design, development, manufacture, usage, and maintenance. Airworthiness is an effective approach to improve aircraft's safety, which is supported by many airworthiness standards and certification criteria. Now, more and more civil and military aircraft-types are considering airworthiness consideration in the process of their design, development, manufacture, usage, and maintenance. Its certification issues frequently make headlines throughout the aerospace industry. Recent news reports regarding test-related challenges for two major civil aircraft (ARJ-21, C-919) have generated significant interest in the civil aviation community in China. In the military airworthiness field, too much loss of aircraft cites several airworthiness factors and makes many recommendations regarding military airworthiness processes [1]. One such finding from the report states, "Airworthiness must be delivered by people who are suitably qualified and experienced and have the right skills and training" [2]. Despite the visibility and importance of airworthiness and the associated engineering standards to both the civil and military aviation communities, it is very meaningful to develop airworthiness academic curricula on these topics in the undergraduate and graduate of engineering and management colleges [1]. Accordingly, FAA, EASA, CAAC and IEEE have called for the integration of standards into the classroom and has recommended methods to incorporate them into engineering and management curricula [3]. The author serves as a Professor in the Equipment Management and Safety Engineering (EMSE) College at Air Force Engineering University. During the 2013-2014 academic year many courses in airworthiness are being offered to graduate students and senior undergraduates in an effort to understand how airworthiness processes and standards might be incorporated into the academic curriculum.

\section{Course Description}

Airworthiness is the measure of an aircraft's suitability for safe flight and is a complicated characteristic between safety and performance. The system safety and physical integrity are two critical technologies for airworthiness engineering. System safety analysis and integrity working should be stressed in aircraft's total life. Meanwhile, Airworthiness process is very complex and should make use of system engineering theory to resolve many management problems, such as management organization, management regulation and management flows. 
Thus, the main objective of the course was to pass on knowledge of the general airworthiness processes for military and civil aircraft and to equip students with a skill set to tailor criteria and get adequate airworthiness requirements based on aircraft configuration, usage, and environment. Meanwhile, some basic management method and engineering guideline about how to plan airworthiness process and to develop system and equipment by airworthiness regulations are given. Lastly, various scenarios about airworthiness for civil and military aircraft are simulated to apply their knowledge of airworthiness management and engineering to the practical systems and equipments.

The course covered four major topics: general airworthiness process considerations for military and civil aircraft, military airworthiness criteria from MILHDBK- 516B "Airworthiness Certification Criteria" [4], system safety assessment process from SAE ARP 4761 "Guideline and methods for conduction the safety assessment process on civil airborne system and equipment" [5], and developing process from ASE ARP4754 "Guideline for development of civil aircraft and system" [6]. Lectures were supplemented with information from CAAC Advisory Circulars and commonly used standards. An outline of the course topics is provided in Table 1. Students were presented with a proposed safety analysis (e.g., Failure Tree Analysis), design change (e.g., the backups design) and management flowing change (e.g. adding airworthiness verifying actions into normal verification) and asked how airworthiness requirements would need to be tailored for these safety analysis, design change and management change. The course required the students to apply their knowledge of the airworthiness process to finish a report about how to carry out airworthiness analysis, design or management associated with the some system or equipment.

Table 1 Airworthiness course topics

\begin{tabular}{|l|l|}
\hline Number of lecture & Topic \\
\hline 2 & Introduction and General Airworthiness Process \\
\hline 1 & System Engineering for Airworthiness process \\
\hline 1 & Integrity for Aircraft \\
\hline 4 & System Safety analysis based on 4761 \\
\hline 12 & Airworthiness standards, certification criteria, MIL-HDBK-516 \\
\hline 4 & Airworthiness process based on 4754 \\
\hline 1 & $\begin{array}{l}\text { Scenarios simulation about airworthiness analysis, design and } \\
\text { management }\end{array}$ \\
\hline
\end{tabular}

\section{Implementation}

Students were divided into some teams and were asked to select an acquainted system (e.g., fly control system) or equipment (e.g., inertial navigation equipment) for use in the final scenarios simulation according to their specialties, respectively. Students were provided with a mission for the selected systems or equipments from which they could be against usage and environmental requirements. Each team used the MIL-HDBK-516 criteria and CCAR-25 as a starting point and then tailored these criteria based on the selected systems or equipments' configuration, usage, and environment. For each applicable criterion, each team chose a standard and method of compliance to generate a proposed airworthiness basis for the selected system or equipment. The proposed airworthiness basis was reviewed by the instructor who acted in the role of "airworthiness authority" for the selected system or equipment. Once the airworthiness basis and certification strategy were approved, each team was responsible for performing the review, analysis, calculation, check or test that they had chosen as verification methods in their certification plan.

From the point of management, the airworthiness management process is totally given for the selected system or equipment, including to the verifying contents, method, date, and order for every applicable criterion. From the point of engineering, the airworthiness technical activities is totally shown for the selected system or equipment, including to the technical requirements, testing tools, 
related software and hardware. Some teams use FTA tool to draw failure tree for the selected systems or equipment in order to find out single point failure, and some teams carry the verifying process for the selected aircrafts or some acquired equipments based on system safety assessment as shown in Figure 1.

Some teams find out the typical non-conformance items for the selected system or equipment as shown in Table 2.Some teams create the Risk Matrix for various likelihoods and severities and provide the corresponding control measurement for the discovered failure conditions as shown in Table 3.

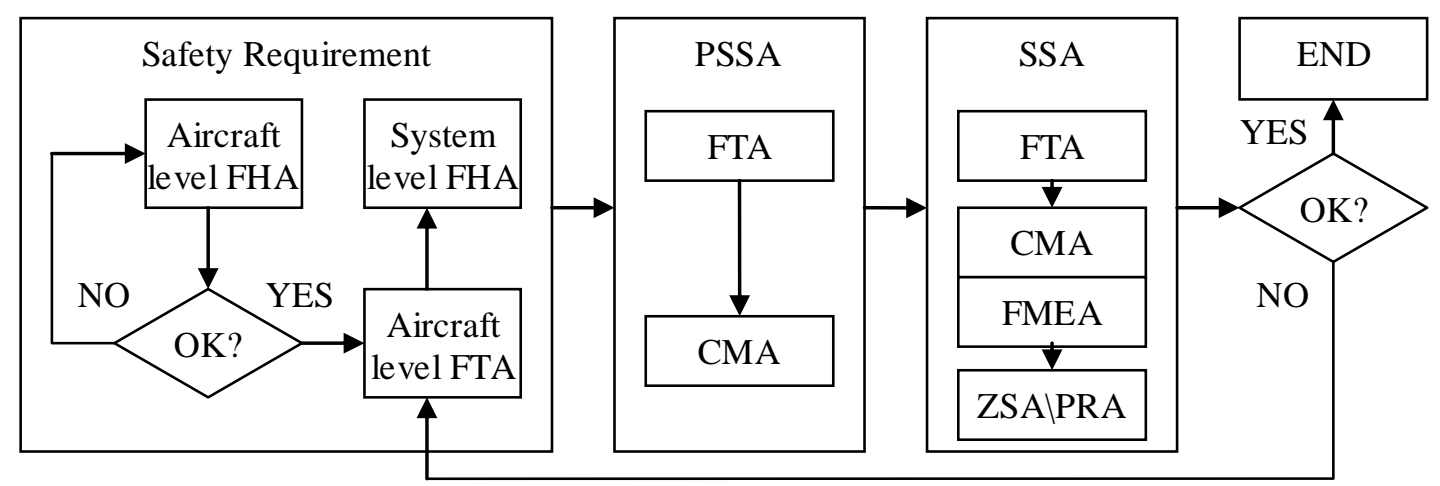

Figure 1 Verifying process based on System Safety Assessment

Table 2 The typical non-conformance items reviewed

\begin{tabular}{|l|l|l|}
\hline Non-conformance items & Regulation & Suggesting \\
\hline $\begin{array}{l}\text { Failure rate of one subsystem } \\
\text { is high. }\end{array}$ & 516B 12.1.3 & $\begin{array}{l}\text { Improve sub-system's } \\
\text { reliability }\end{array}$ \\
\hline $\begin{array}{l}\text { Failure component can not } \\
\text { find out according to alarms. }\end{array}$ & $\begin{array}{l}\text { 516B 16.1.7 } \\
\text { AC 25.1309-1A }\end{array}$ & $\begin{array}{l}\text { Alarm's logics should be } \\
\text { more clear }\end{array}$ \\
\hline $\begin{array}{l}\text { Testing pressure and limited } \\
\text { pressure should be arranged. }\end{array}$ & $\begin{array}{l}\text { CCAR 25.1435 } \\
\text { 516B 8.1.8 }\end{array}$ & $\begin{array}{l}\text { Understand the regulation's } \\
\text { requirement more clearly . }\end{array}$ \\
\hline $\begin{array}{l}\text { Failure-safe design should be } \\
\text { simple. }\end{array}$ & $\begin{array}{l}\text { CCAR-25.671 } \\
\text { 516B 6.1,9.4 }\end{array}$ & $\begin{array}{l}\text { Understand the regulation's } \\
\text { requirement more clearly. }\end{array}$ \\
\hline
\end{tabular}

Table 3 Failure Conditions' severities and likelihoods associated control measurement

\begin{tabular}{|l|l|l|l|}
\hline Failure conditions & Severities & Likelihood & Control Measurement \\
\hline Power energy cut & Catastrophic & occasional & Re-design \\
\hline Power energy limit & Critical & occasional & Passive safety Device \\
\hline $\begin{array}{l}\text { Attack angle conductor } \\
\text { moving barriers }\end{array}$ & Marginal & remote & Active safety Device \\
\hline $\begin{array}{l}\text { One of four Computer work } \\
\text { normally }\end{array}$ & Negligible & occasional & Warning Device \\
\hline
\end{tabular}

Overall the students' performance on the final paper was appealing. All teams demonstrated the ability to follow the airworthiness process by reviewing the airworthiness requirement based on MIL-HDBK-516B and CCAR-25 to the selected systems or equipment based on specified usage and environment, proposing standards for each criterion's analyzing, checking or testing compliance with the standards. Each team presented detailed describes for airworthiness approvals based on their work. Students seemed enthusiastic about applying the classroom knowledge to a practical challenge. Furthermore, it was observed that because the students did not have pre-conceptualized set of airworthiness requirements (as would be the case for an engineer and a manager experienced aircraft technology and management standards), they would like to consider 
with regard to proposing airworthiness standards and methods of compliance for commercially available system or equipment.

\section{Conclusions}

A lot of feedbacks from the airworthiness course were positive and constructive. Students noted that the course provided a different perspective than other courses offered in the EMSE. Students indicated that a formal textbook would be helpful for a follow-on offering of the course since the MIL-HDBK-516 and CCAR-25 are cumbersome to apply in an academic context. Based on these feedbacks, the authors met with the EMSE curriculum committee to discuss how to best incorporate airworthiness considerations into the undergraduate and/or graduate EMSE curriculum. One idea under consideration was to add airworthiness related assignments to some of the key undergraduate classes. Additionally, elements of airworthiness - such as the systems engineering approach in design and system safety analysis - already exist in the senior design courses. These elements could be adapted or modified to achieve a focused airworthiness thrust in these capstone courses. While the exact method of incorporating airworthiness considerations into the curriculum remains in work, it is believed that the result will be under-graduate and graduate curricula that are well-positioned to meet the demands of engineers and manages that are equipped to meet real-world challenges in aircraft design and airworthiness. It is recommended how other engineering and management colleges consider airworthiness considerations incorporated into their curricula.

\section{Acknowledgments}

The authors are grateful for the active, enthusiastic participation of the students in the class. The authors thank Mr. LiLiang and Dr. LiFei for their interest and continued support in this area. The authors also thank Mr. QiuKai for his verification experiences of reviewing, analysis, calculating, checking and testing for some-new-type aircraft.

\section{References}

[1] Stephen P. Cook and Charies E. Hall Jr. Incorporating Airworthiness into the Academic Curriculum, 48TH AIAA Aerospace Sciences Meeting including the New Horizons Forum and Aerospace Exposition, 4-7 January 2010, Orlando, Florida.

[2] Haddon-Cave, Charles. The Nimrod Review. 28 October 2009. Crown Copyright 2009.

[3] Kowalenko, Kathy. "IEEE Calls for Integrating Standards Into Engineering Curriculum." The Institute, November 2009.

[4] Department of Defense Handbook MIL-HDBK-516B, Airworthiness Certification Criteria. 26 September 2005.

[5] ASE ARP 4761, Guidelines and methods for conduction the safety assessment process on civil airborne systems and equipment, 1996-12.

[6] ASE ARP 4754, Guidelines for development of civil aircraft and systems, Revised, 2012-12.

[7] Department of Defense Handbook MIL-HDBK-515, Weapon system integrity Guide, 2002,11.

[8] Department of Defense Handbook MIL-HDBK-87244 (USAF),MILITARY HANDBOOK, AVIONICS/ELECTRONICS INTEGRITY, 1995-1. 